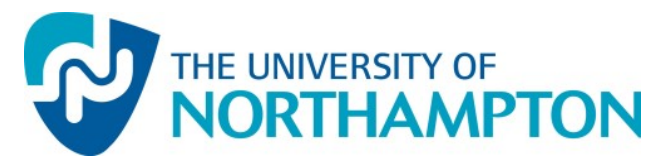

This work has been submitted to NECTAR, the Northampton Electronic Collection of Theses and Research.

\section{Article}

Title: Analysis of electrochemical noise measurement

Creators: Jamali, S. S., Mills, D. J., Cottis rand

DOI: $10.1016 /$ j.porgcoat.2016.01.

Example citation: Jamali, s. S. fills, D. J., Cotth R. A. and Lan, T. Y. (2016)

Analysis of electrochemi roise easure ent on an organically coated metal.

Progress in Organic atings $96 \quad 0.52 \quad 0300-9440$.

It is advisable to er to publianer's version if you intend to cite from this work.

Version:

Official URL: tp://Wurw.sciencedirect.com/science/article/pii/S0300944016300662

Note:

\section{(c) $($ i) $(9)$}

This work is licensed under a Creative Commons Attribution-NonCommercial-NoDerivs 3.0 Unported License.

http://nectar.northampton.ac.uk/9266/

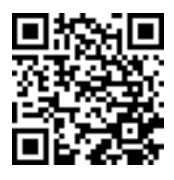




\title{
Analysis of electrochemical noise measurement on an organically coated metal
}

\author{
Sina S Jamali ${ }^{1 *}$, Douglas J Mills², Robert A Cottis ${ }^{3}$, Tian Yang Lan ${ }^{2}$ \\ ${ }^{1}$ ARC Research Hub for Australian Steel Manufacturing, Faculty of Engineering \& \\ Information Sciences, University of Wollongong, Northfields Avenue, Wollongong, NSW \\ 2522 Australia \\ ${ }^{2}$ School of Science and Technology, University of Northampton, St George's Avenue, \\ Northampton, NN2 6JD, UK \\ ${ }^{3}$ The School of Materials, University of Manchester, Oxford Road, Manchester, M13 9PL, \\ UK \\ *Corresponding author: sjamali@uow.edu.au, +61(0) 426736630
}

\begin{abstract}
Electrochemical noise measurement (ENM) has found a credible place among the electrochemical methods applied to organic coatings, with a large number of reports in the literature of using the technique as a reliable method for the evaluation of the corrosion protection afforded by an organic coating on a metal surface. This has commonly been performed by calculating the noise resistance, $R_{n}$, or spectral noise resistance, $R_{s n}$, from the two main elements of electrochemical noise signal, the electrochemical current noise and potential noise. Several studies have shown that in practice $R_{n}$ is a good measure of corrosion protection provided by an organic coating and affords good agreement with other measures of corrosion resistance from more established methods such as electrochemical impedance spectroscopy and DC resistance measurement. However, the theory of the electrochemical noise signal has not been fully analysed to elucidate the influence of the coating on the noise acquired. In this study a mathematical model is advanced in accordance with the equivalent electrical model in an electrochemical system consisting of a corroding metal substrate which has on it an organic coating. Experiments are also performed to evaluate the presented model in practice. Results of both theoretical and physical modelling show that potential noise is not influenced by the effect of coating while the current noise is attenuated due to the large impedance of coating.
\end{abstract}

\section{Introduction}

Electrochemical Noise Measurement (ENM) is a non-destructive/non-intrusive technique capable of monitoring basic changes in an electrochemically active system. The method 
measures the fluctuation in the current produced by electrochemical reactions (e.g. iron dissolution $\left(2 \mathrm{Fe} \rightarrow 2 \mathrm{Fe}^{++}+4 \mathrm{e}\right)$, oxygen reduction $\left(2 \mathrm{H}_{2} \mathrm{O}+\mathrm{O}_{2}+4 \mathrm{e} \rightarrow 4 \mathrm{OH}^{-}\right)$as well as the effect of this fluctuation on the electrochemical potential of system. Much work has been done on bare (uncoated) metal ENM [1-5] showing that $\mathrm{R}_{\mathrm{n}}$ is a reliable measure of corrosion resistance and that EN data may be able to determine the type of corrosion [6-8]. However when it comes to metal coated with an organic coating, although the ease with which the above electrochemical reactions go on may well control the rate with a defective organic coating, what is more commonly found is that the rate of transport of ions (e.g. sodium and chloride) through the polymer film is the rate determining process controlling the overall rate of the corrosion reaction. The faster the transport the lower the protection afforded to the metal and vice versa. ENM may be implemented in order to acquire information about coating integrity and degradation mechanism in coated systems. The degradation process of a paint coating may be analysed by contributions from charge transfer reactions at high frequencies and mass transport reactions at low frequencies [9].

Studies have combined ENM with multi-electrode systems [10-13] as well as embedded electrodes [14] in attempt to obtain mechanistic information about corrosion process under an organic coating. Also a variety of analytical methods such as statistical functions $[15,16]$, wavelet analysis [17-19], fractal analysis [20-22], artificial neural network [23,24], cluster and discriminant $[25,26]$ and shot noise analyses [27] have been implemented mainly in order to acquire mechanistic information about the under-film corrosion process such as active/passive state of substrate, formation of corrosion product and the corrosion type taking place at the organic coating/metal interface. However, in coated metal systems with even a moderately protective organic coating, the current and hence the current noise is mainly controlled by transport of ionic species through the organic film. Despite the above empirical efforts that have been made to extract mechanistic information from ENM on an organically coated metal, little has been done to understand the origin of electrochemical noise from a coated metal and how it is altered by the coating system. This study presents a theoretical model that might hold the key to a meaningful interpretation of electrochemical noise from coated metal and hence the acquisition of mechanistic information about corrosion processes. This is tested against a physical model.

\section{Theoretical Model}

In order to understand the electrochemical noise generated from a complex electrochemical system such as a corroding organically coated metal coated, it is essential to break down the complex system into more understandable electrical components known as an equivalent electrical circuit (EEC). A simple Randles circuit without diffusion, i.e. no Warburg term, with an element comprising a time constant, $R C$, for the organic coating and a resistor for the solution impedance has been used previously $[28,29]$ for modelling an organically coated metal that generates electrochemical noise. The capacitance simulates the capacitive characteristic of the organic coating $\left(\mathrm{C}_{\mathrm{c}}\right)$ and the resistance corresponds to the ionic resistance of coating film $\left(\mathrm{R}_{\mathrm{f}}\right)$. Figure 1, reproduced from Ref. [28], illustrates the schematic cell 
configuration for the salt bridge electrode arrangement and the associated electrical circuit using a Randles circuit to model each coated area of metal. However, the Randles circuit assumes the coatings to be defectless and with no disbondment from the metal substrate. This does not normally hold true in "real world" scenarios where the coating may contain or evolve significant ionic pathways (sometimes known as "pores") that leads electrolyte towards the substrate surface and introduces a second time constant to the ECC associated with the double layer capacitance $\left(\mathrm{C}_{\mathrm{dl}}\right)$ and charge transfer resistance $\left(\mathrm{R}_{\mathrm{ct}}\right)$ at the metal surface. This time constant is considered in series with the coating resistance and in parallel with the coating capacitance. The $\mathrm{C}_{\mathrm{dl}}$ and $\mathrm{R}_{\mathrm{ct}}$ of this case are confined to a small area where the ionic pathway meets the metal substrate. Also in many cases significant coating disbondment occurs due to the wet interface and the corrosion domain spreading underneath the coating, in which case the impedance associated with $\mathrm{C}_{\mathrm{dl}}$ and $\mathrm{R}_{\mathrm{ct}}$ at the metal-solution interface, $Z_{\mathrm{m}-\mathrm{s}}$, is considered in series with the coating impedance, $Z_{\mathrm{f}}$. Figure 2 demonstrates an EEC for ENM in a three electrode configuration using a low noise saturated calomel electrode (SCE) as reference electrode and two metal substrates with fully disbonded coating films as working electrodes. This model is adopted from the previous work on modelling electrochemical noise measurement [30-32] for a current noise based model. Note that the solution resistance for the solution within the gap between metal and coating is not taken into account in the model as this usually is a very small gap and the solution is of high ionic activity with very low resistance.
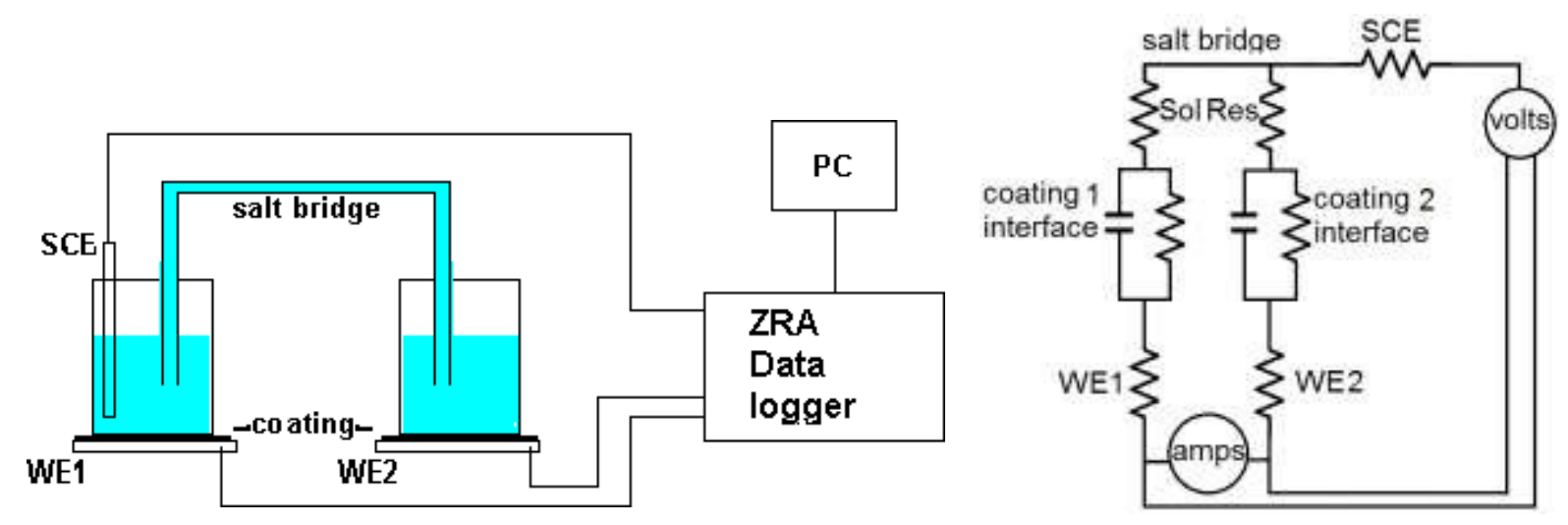

Figure 1 Standard salt bridge arrangement (left) for electrochemical noise measurement on two organically coated metal surfaces and the associated equivalent electrical circuit (right) assuming Randles circuit modelling the coated metal. WE1 and WE2 refer to working electrodes 1 and 2 respectively. [28] 


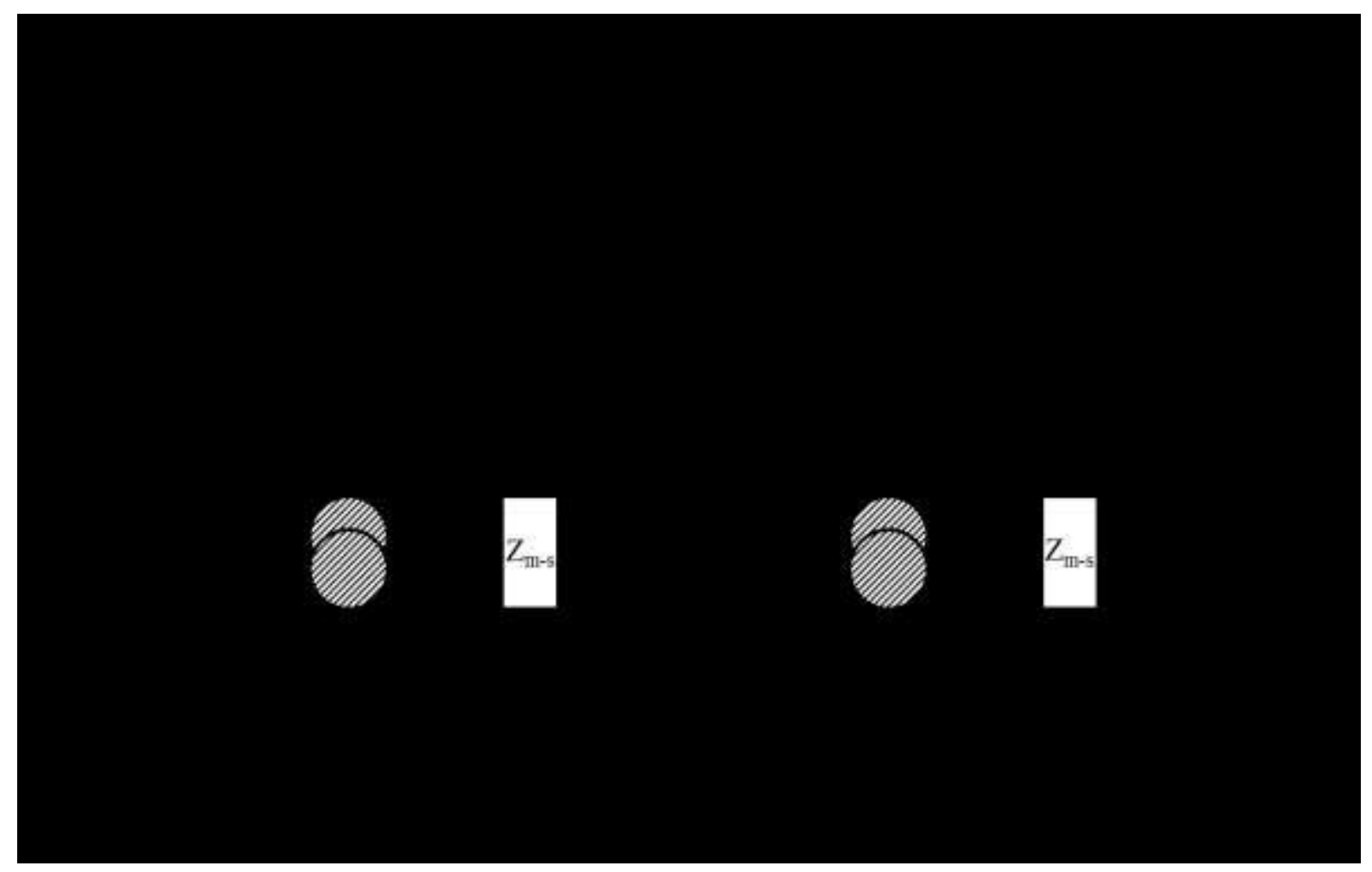

Figure 2 Equivalent electrical circuit (EEC) simulating a three-electrode (WE1, WE2 and Ref) noise measurement configuration for a detached organic coating from a corroding metal substrate.

In the EEC presented in Figure 2, no hindrance is introduced by coating between anodic and cathodic sites underneath the disbonded coating and therefore electrochemical reactions and thus generation of electrochemical noise occur independently from the organic coating. The electrochemical noise measured via ZRA and potentiometer in a standard three electrode configuration however is altered by the coating impedance. Current noise is produced as a result of anodic and cathodic reactions underneath the coating. Potential noise is a consequence of current noise acting on the impedance of the metal-solution interface [31]. The cathodic process of oxygen reduction may be rate controlling for coatings of low oxygen permeability, but commonly the oxygen permeability is sufficient that the film does not limit oxygen transport to the metal. In the case of hydrogen evolution as the cathodic reaction, the kinetics of the electrochemical reaction is usually rate-controlling, although the transport of water could be important for low permeability coatings. Organic coatings protect metal from corrosion by providing a barrier against the flow of corrosive ions, e.g. chloride, towards the metal substrate and by introducing a large impedance between anodic and cathodic sites hence impeding the electrochemical process of corrosion. In this paper a fully detached organic coating is discussed where the coating does not isolate anodic and cathodic sites and therefore the only protective effect is by limiting the flow of ions towards and from the metal substrate. The electrolyte under the film is aerated, hence simulating a coating of high oxygen permeability. In the real case scenario of disbonded coating on a metal surface this can effectively change the electrolyte composition underneath the coating which in turn can 
results in alteration of form and mechanisms of corrosion, e.g. passivation of metal once interfacial electrolyte has become adequately alkaline. However, in the physical model studied in this work, large volume of solution does not allow for low ionic permeability of coating to effectively change the solution composition.

This model studies in this work, presented in Figure 2, considers that a noise-free reference electrode is used and therefore the resultant potential noise is produced solely by the two working electrodes. If a coated electrode similar to working electrodes 1 and 2, WE1 and WE2 respectively, were used as reference electrode its potential noise power will add to the overall potential noise power [31]. The measured current noise of one working electrode is produced by the current from one electrode to the other. For identical electrodes, i.e. $Z_{\mathrm{m}-\mathrm{s} 1}=$ $\mathrm{Z}_{\mathrm{m}-\mathrm{s} 2}$, in the absence of coating and solution resistance, the current generated by WE2 will be halved, with one half flowing towards WE2 and the other half dissipating in electrochemical, i.e. anodic or cathodic, processes [33]. Only the current that flows towards the second working electrode is detectable by ZRA and is measured as current noise power. Therefore, the current noise power of each of the identical electrode will be given by equation 1 ,

$\frac{t^{2}}{n \text { measured }}=\frac{I \frac{2}{n}}{4}$

where

$I_{n \text { measured }}=$ current noise recorded by the ZRA

$\overline{I_{n}^{2}}=$ mean squared noise current or current noise power

Assuming the currents from the two electrodes are uncorrelated, the current noise power resulting from the two identical electrodes is the sum of current noise power produced by each electrode and is given by equation 2 ,

$$
\frac{2}{n \text { measured }}=\frac{I^{2}}{\frac{2}{2}}
$$

In presence of solution resistance, the proportion of current from one electrode to the other will be reduced due to the additional solution resistance in the circuit. Therefore the measured current noise power will be reduced and is given by equation 3 [31], 
$T_{n \text { measured }}^{2}=2\left(\frac{Z^{m-s}}{R_{S}+2 Z_{m-s}}\right)^{2} \cdot I_{n^{2}}$

where

$R_{S}=R_{\text {sol1 }}+R_{\text {sol } 2}$

Similarly in the presence of additional coating resistances, the current between the two electrodes will be further reduced proportional to $\frac{Z_{m-s}}{2 Z_{m-s}+2 R_{S}+2 Z_{f}}$ and the resulting power noise power will be given by equation 4 ,

$$
\begin{aligned}
& \overline{I_{n \text { measured }}^{2}}=\left(\frac{Z_{m-s .1}}{R_{S}+Z_{m-s .1}+Z_{f .1}+Z_{m-s .2}+Z_{f .2}}\right)^{2} \cdot \overrightarrow{I_{n 1}}+\left(\frac{Z_{m-s .2}}{R_{S}+Z_{m-s .1}+Z_{f .1}+Z_{m-s .2}+Z_{f .2}}\right)^{2} \cdot \overrightarrow{I_{n 2}} \\
& \overline{I_{n \text { measured }}^{2}}=\left(\frac{Z_{m-s .1} \cdot I_{n 1}+Z_{m-s .2} \cdot I_{n 2}}{R_{S}+Z_{m-s .1}+Z_{f .1}+Z_{m-s .2}+Z_{f .2}}\right)^{2}
\end{aligned}
$$

where

$Z_{m-s .1}$ and $Z_{m-s .2}$ are metal-solution impedances of WE1 and WE2 respectively and $Z_{f .1}$ and $Z_{f .2}$ are impedances associated with coating films on WE1 and WE2 respectively.

Equation 4 can be simplified for the case of symmetric (identical) electrodes in the form of equation 5. Herein three possible sources of electrodes asymmetry, i.e. non-identical metalsolution impedance, coating resistance and solution resistance, have been assumed symmetrical to simplify equation 4 .

$$
\underset{n \text { measured }}{t^{2}}=2\left(\frac{Z^{m-s}}{2 Z_{m-s}+R_{S}+2 Z_{f}}\right)^{2} \cdot I_{n}^{2}
$$

The potential noise power in the absence of coating resistance, e.g. the measurement set-up presented in Figure $3 \mathrm{a}$, is produced by the current acting on the interfacial impedance $\left(\mathrm{Z}_{\mathrm{m}-\mathrm{s}}\right)$ at the surface of the electrode that generates the current, in parallel with the solution resistance and polarisation resistance of the second electrode. The potential noise power for one source of current, i.e. one working electrode, is given by equation 6 [31], 
$\overline{E_{n}{ }^{2}}=\frac{\overline{I_{n}^{2} Z_{m-s}}}{4}$

Where

$\overline{E_{n}^{2}}=$ mean squared potential noise or potential noise power,

$\overline{I_{n}^{2}}=$ mean squared current noise or current noise power, and

$Z_{m-s}=$ interfacial impedance at metal surface,

In order to calculate potential noise power in presence of coating impedances, similar to the previous study [31], the effects of each source of current should be analysed independently, with all other voltage sources treated as short-circuit and current sources as open-circuit. Considering the current noise source $I_{n 1}$ on WE1, the current $I_{n 1}$ will be split between the $Z_{m}$ s.1 and the chain of $Z_{\mathrm{f} .1}+\mathrm{R}_{\text {sol1 }}+\mathrm{R}_{\text {sol.2 }}+\mathrm{Z}_{\mathrm{f} .2}+\mathrm{Z}_{\mathrm{m} \text {-s.2. }}$. Using $\|$ to indicate parallel impedances and + to indicate series impedances, $\mathrm{I}_{\mathrm{n} 1}$ will be applied to an impedance $Z_{\mathrm{m}-\mathrm{s} .1} \|$ $\left(\mathrm{Z}_{\mathrm{f} .1}+\mathrm{R}_{\mathrm{sol} 1}+\mathrm{R}_{\mathrm{sol} .2}+\mathrm{Z}_{\mathrm{f} .2}+\mathrm{Z}_{\mathrm{m}-\mathrm{s} .2}\right)$, hence producing a voltage $\mathrm{E}_{1}=\mathrm{I}_{\mathrm{n} 1} \times\left(\mathrm{Z}_{\mathrm{m}-\mathrm{s} .1} \|\right.$ $\left.\left(Z_{\mathrm{f} .1}+R_{\text {sol1 }}+R_{\text {sol.2 }}+Z_{\mathrm{f} .2}+Z_{\mathrm{m}-\mathrm{s} .2}\right)\right)$ at the junction between $\mathrm{I}_{\mathrm{n} 1}, \mathrm{Z}_{\mathrm{m} \text {-s.1 }}$ and $\mathrm{Z}_{\mathrm{f} .1}$. The potential will be measured using the reference electrode at the junction between $R_{\text {sol.1 }}$ and $R_{\text {sol.2, }}$, so we have to allow for the potential divider. Equation 7 gives the voltage noise produced by one working electrode (WE1),

$E_{m-s .1}=E_{1} \times \frac{R_{s o l .2}+Z_{f .2}+Z_{m-s .2}}{R_{s o l .1}+Z_{f .1}+R_{s o l .2}+Z_{f .2}+Z_{m-s .2}}$

Replacing $E_{1}$ with $\mathrm{I}_{\mathrm{n} 1} \times\left(\mathrm{Z}_{\mathrm{m} \text {-s.1 }} \|\left(\mathrm{Z}_{\mathrm{f} .1}+\mathrm{R}_{\mathrm{sol} 1}+\mathrm{R}_{\text {sol.2 }}+\mathrm{Z}_{\mathrm{f} .2}+\mathrm{Z}_{\mathrm{m} \text {-s. } 2}\right)\right)$ results in equation 8 for potential noise with asymmetric electrodes and coating film impedances,

$E_{m-s .1}=I_{n 1} \times\left(\frac{Z_{m-s .1} \times\left(R_{s o l .2}+Z_{f .2}+Z_{m-s .2}\right)}{Z_{m-s .1}+R_{s}+Z_{f .1}+Z_{f .2}+Z_{m-s .2}}\right)$

For a symmetric configuration, i.e. $\mathrm{Z}_{\mathrm{m}-\mathrm{s}}=\mathrm{Z}_{\mathrm{m} \text {-s. } 1}=\mathrm{Z}_{\mathrm{m}-\mathrm{s} .2}, \mathrm{Z}_{\mathrm{f}}=\mathrm{Z}_{\mathrm{f} .1}=\mathrm{Z}_{\mathrm{f} .2}$ and $\mathrm{R}_{\text {sol. } 1}=\mathrm{R}_{\text {sol. } 2}=$ $\mathrm{R}_{\mathrm{s}} / 2$, equation 8 simplifies to,

$E_{m-s}=\frac{I_{n} \times Z_{m-s}}{2}$ 
Therefore the potential noise power as a result of the two identical working electrodes is given by equation 10 ,

$\overline{E_{n}^{2}}=\frac{\overline{P_{i n} \times} \stackrel{2}{m-s}}{2}$

The noise resistance defined by the ratio of the standard deviations of the potential and current noise:

$$
R_{n}=\sqrt{\frac{E^{\overline{2}}}{\overline{I_{n}{ }^{2}}} \sqrt{ } \frac{\overline{\left(2 Z_{m-s}+R_{s}+2 Z\right)^{2}}}{4}}
$$

$$
=\frac{R_{s}}{2}+Z_{m-s}+Z_{f}
$$

In comparison the $\mathrm{R}_{\mathrm{n}}$ in the absence of coating film by replacing $\sigma_{V}$ and $\sigma_{I}$ from equations 2 and 6 is given by equation 12 ,

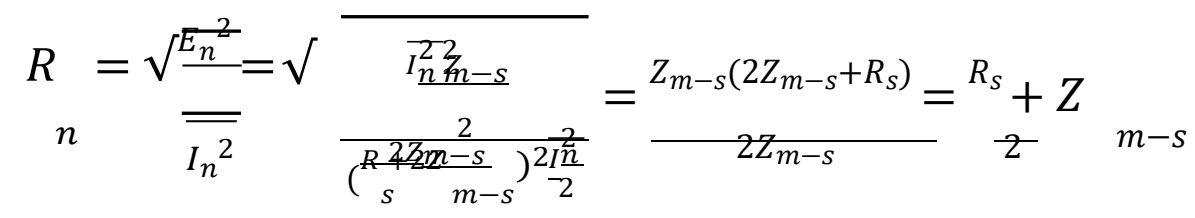

\section{Physical Model}

In order to replicate the under-film corrosion with a coating detached from the metal surface, with an EEC as shown in Figure 2, a physical model based on the "double U-cell" set up shown in Figure 3 was used. Each U-cell accommodates a detached coating film in between the glass half cells with steel bars in one of the half cells serving as working electrodes. This set-up simulates a delaminated coating in contact with a controllable electrolyte. Figure 4 represents the EEC that models the double U-cell set-up. Figure 3a demonstrates the set-up for "under-film" ENM where the standard three electrode measurement between WE1$1+\mathrm{WE} 1-2$ and RE1 provide current and potential noise in cell $1^{1}$. Clearly the coating

${ }^{1}+$ : coupled via ZRA 
impedance has no role in this under-film measurement. Figure $3 \mathrm{~b}$ shows the set-up for "through-film" ENM where the ZRA measurement between WE1-1+WE1-2 (electrically coupled/wired) and WE4-1+WE4-2 provides the current noise data. Potentiometric measurement between WE1-1+WE1-2+WE4-1+WE4-2 and RE2 provides the potential noise data.

All measurements were made in $0.5 \mathrm{M} \mathrm{NaCl}$ solution at ambient temperature. Free (detached) films of an alkyd maintenance paint were placed within the U-cells. Two pieces of coating with as near as possible the same resistance were used (nonetheless due to the variability of ionic resistance between nominally identical areas of coating, this was possible only to within a factor of two or three). Mild steel bars were used as working electrode in all experiments. Saturated calomel electrode (SCE) was used as reference electrode in all experiments. Resistance value of coatings was defined prior to testing using a DC electrometer in a two electrode arrangement with a single U-cell and two SCEs (for details see reference [34]). Noise measurement was conducted at $2 \mathrm{~Hz}$ sampling frequency with a total of 512 data points collected in 256 seconds. In order to obtain the detached film, the liquid alkyd paint was applied on a non-stick PTFE (polytetrafluoroethylene) sheet using the spreader bar and carefully delaminated after it was fully dried. 


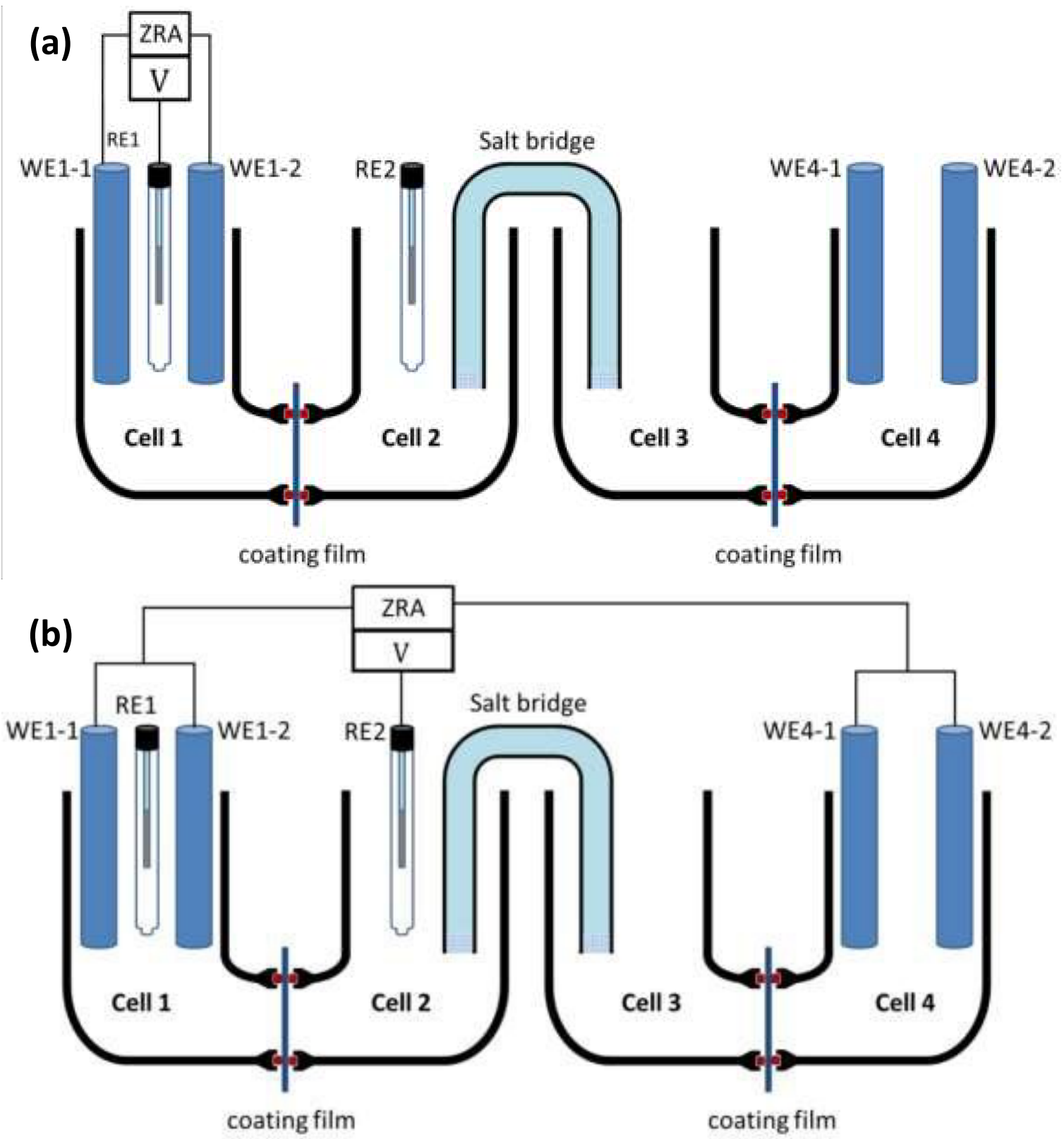

Figure 3 Electrode set up for simulation of under-film corrosion condition. 


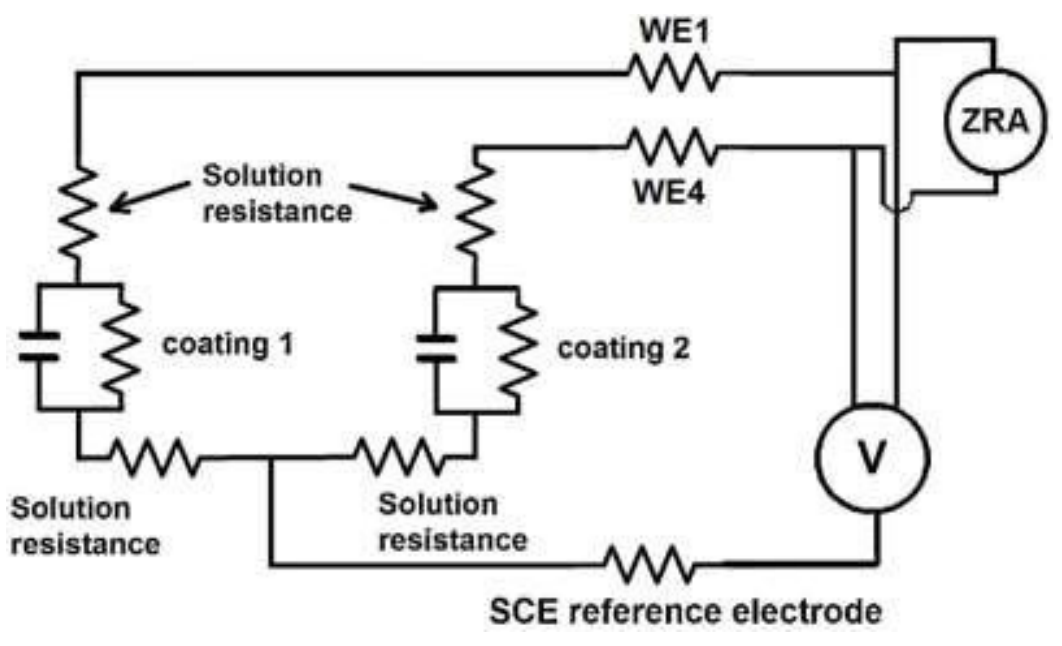

Figure 4 Electrical equivalent circuit for "through coating" ENM with fully detached organic coatings from metal surfaces. WE1 and WE4 are the coupled WE1-1+WE1-2 and WE41+WE4-2 respectively.

Table 1 presents results of ENM for under-film set-up without coating film (Fig.3a) and also for through-film set-up with coating films between WEs and RE (Fig.3b). Results of throughfilm set-up are given for two different sets of coating resistances. A GillAC (manufactured by ACM) potentiostat/galvanostat/ZRA was used for ENM. Each ENM experiment gathered 1024 data points at $2 \mathrm{~Hz}$ sampling frequency. The instrument was assessed according to the guidelines given in references $[35,36]$ to check the significance of instrumental noise on the gathered electrochemical data. Resistors with resistance values similar to the coating resistances were used in a dummy cell with "star-arrangement" (see reference [35] for more detail). Analysis of instrument indicated an absence of anti-aliasing filter in the data acquisition system and instrumental noise larger than the thermal noise level of the resistors used in the construction of dummy cell. However, the level of instrumental noise was significantly smaller than the level of electrochemical noise generated by the corroding system investigated herein. DC drift was removed from raw data before calculation of $R_{n}$ using ENANALIZ program (developed by R.A. Cottis) that implemented a linear detrend algorithm. The area of the electrodes in the through-film measurement was twice that in the under-film measurement and this effect was compensated for mathematically by increasing the $\sigma_{I}$ by a factor of $\sqrt{2}$ - while reducing the $\sigma_{V}$ by the factor of $\sqrt{2}$ thus reducing the measured $R_{n}$ by the factor 2 . The current noise power is proportional to the electrode surface area while the potential noise power is inversely proportional to the electrode surface area.

Values of $R_{n}$ do not match the $R_{D C}$ values of the two coatings in each experiment and although $R_{n}$ and $R_{D C}$ are not equal, they follow the same trend (the larger $R_{D C}$, the larger $R_{n}$ ). Dissimilarity of $R_{n}$ and $R_{D C}$ might be due to the difference in the nature of measurements by a DC electrometer and ENM. The DC electrometer applies a small bias current and measures the potential drop between the two working electrodes as a result of this external bias current 
whereas in ENM no bias current or potential is applied. Also by definition $\mathrm{R}_{\mathrm{DC}}$ corresponds to the low frequency limit of noise resistance in the frequency domain $\left(R_{s n}(f)\right)$ whereas the $R_{n}$ values in table 1 are calculated in the time domain with sampling frequency of $2 \mathrm{~Hz}$. Also it should be noted that although it is not expected that $\mathrm{Rn}_{\mathrm{n}}$ measures an average value of the $\mathrm{R}_{\mathrm{DC}}$ of the two coating, as shown in equation 5 , the $R_{n}$ is influenced by the impedance of the both coatings.

Table 1 Results of ENM for under-film and through-film electrode set-ups using steel bar as working electrode and detached film of alkyd coating as the main source of impedance.

\begin{tabular}{cccccc}
\hline Set-up & $\sigma_{I}(\mu \mathrm{A})$ & $\sigma_{V}(\mu \mathrm{V})$ & $\begin{array}{c}\mathrm{R}_{\mathrm{n}} / 2 \\
\text { ohm.cm }\end{array}$ & $\begin{array}{c}\text { Coating } 1 \mathrm{R}_{\mathrm{DC}} / \\
\text { ohm.cm }\end{array}$ & $\begin{array}{c}\text { coating 2 } \mathrm{R}_{\mathrm{DC}} / \\
\text { ohm.cm }\end{array}$ \\
\hline under-film ENM & $2.66 \mathrm{E}+00$ & $2.86 \mathrm{E}+03$ & $1.07 \mathrm{E}+03$ & & \\
through-film ENM & $1.1 \mathrm{E}-03$ & $1.7 \mathrm{E}+03$ & $1.55 \mathrm{E}+06$ & $1.30 \mathrm{E}+06$ & $3.00 \mathrm{E}+05$ \\
through-film ENM & $2.31 \mathrm{E}-06$ & $1.56 \mathrm{E}+03$ & $6.75 \mathrm{E}+08$ & $3.00 \mathrm{E}+08$ & $7.00 \mathrm{E}+09$ \\
\hline
\end{tabular}

The important implication of the results in table 1 is that the presence of a coating does not alter the potential noise while it produces a significant change in the current noise. This is in agreement with the theoretical model, confirming that the potential noise is unaffected by the presence of coating and the main role of the coating is attenuation of the current between the workings electrodes. This conclusion from these results is of course only valid for the fully delaminated coating and other scenarios need to be studied individually in order to determine the effect of organic coatings on the electrochemical noise signal. The theoretical and physical models are both somewhat simplified, since they assume a fully disbonded coating with rapid oxygen transport through the coating, but with no underfilm conduction between the two measuring cells. In addition the large 'underfilm' solution volume in the physical model limits changes in solution composition, which may be important in thin solution layers under disbonded coatings.

\section{Conclusions}

A mathematical model has been developed to evaluate the effect of coating impedance on potential and current noise signals and the derived noise resistance. The model suggests that potential noise is not influenced by the coating impedance while the current noise is attenuated by the impedance of coating.

In order to test the theoretical model, a physical model has been designed using $U$ shape glass cells and steel bars to simulate a fully disbonded coating/metal substrate system. Electrochemical noise measurements were made for steel bars with and without the coating impedance introduced between the working electrodes. Physical model showed that coating 
impedance attenuates current noise mainly and has insignificant effect on the potential noise. Hence with the assumptions made hare, the EN measurement of coating resistance is an indicative of ionic resistance of the organic coatings. Further work is necessary to evaluate different corrosion scenarios (e.g. passivation, active pitting etc) in a range of environments using ENM and investigate the possibility of revealing under-film corrosion type and rate.

\section{References}

[1] B. Lengyel, L. Mészáros, G. Mészáros, E. Fekete, F. Janaszik, I. Szenes, Electrochemical methods to determine the corrosion rate of a metal protected by a paint film, Prog. Org. Coat. 36 (1999) 11-14.

http://www.sciencedirect.com/science/article/pii/S0300944098000861 (accessed October 10, 2012).

[2] J.E. Chen, W.F. Bogaerts, The physical meaning of noise resistance, Corros. Sci. 37 (1995) 1839-1842.

[3] D.L. Reichert, Electrochemical noise measurement for determining corrosion rates, in: J.R. Kearns, J.R. Scully, P.R. Roberge, D.L. Reichert, J.L. Dawson (Eds.), Electrochem. Noise Meas. Corros. Appl., ASTM, Philadelphia, PA, 1996: pp. 79-92.

[4] J. Mojica, E. Garcia, F.J. Rodriguez, J. Genescá, Evaluation of the protection against corrosion of a thick polyurethane film by electrochemical noise, Prog. Org. Coat. 42 (2001) 218-225.

[5] D.J. Mills, S.J. Mabbutt, G.P. Bierwagen, Investigation into mechanism of protection of pigmented alkyd coatings using electrochemical and other methods, Prog. Org. Coat. 46 (2003) 176-181. doi:10.1016/S0300-9440(02)00187-X.

[6] H.A.A. Al-Mazeedi, R.A. Cottis, A practical evaluation of electrochemical noise parameters as indicators of corrosion type, Electrochim. Acta. 49 (2004) 2787-2793. doi:10.1016/j.electacta.2004.01.040.

[7] Y.J. Tan, Sensing localised corrosion by means of electrochemical noise detection and analysis, Sens. Actuators, B-Chem. 139 (2009) 688-698. doi:10.1016/j.snb.2009.03.061.

[8] Y.F. Cheng, M. Wilmott, J.L. Luo, The role of chloride ions in pitting of carbon steel studied by the statistical analysis of electrochemical noise, Appl. Surf. Sci. 152 (1999) 161-168. doi:10.1016/S0169-4332(99)00328-1.

[9] J.M. Sanchez-Amaya, R.M. Osuna, M. Bethencourt, F.J. Botana, Monitoring the degradation of a high solids epoxy coating by means of EIS and EN, Prog. Org. Coat. 60 (2007) 248-254. doi:10.1016/j.porgcoat.2007.07.020.

[10] M. Metikos-Hukovic, M. Loncar, C. Zevnik, Monitoring the electrochemical potential noise produced by coated metal electrodes, Mater. Corros. 40 (1989) 494-499. 
[11] G.P. Bierwagen, V. Upadhyay, Attempting to Locate Defects in Coating using Embedded Electrodes, in: Corros. 2012, NACE International, Houston, TX, 2012: pp. C2012-1653.

[12] Y.J. Tan, Y. Fwu, K. Bhardwaj, Electrochemical evaluation of under-deposit corrosion and its inhibition using the wire beam electrode method, Corros. Sci. 53 (2011) 12541261. doi:10.1016/j.corsci.2010.12.015.

[13] N.N. Aung, W.K. Wai, Y.J. Tan, A novel electrochemical method for monitoring corrosion under insulation, Anti-Corrosion Methods Mater. 53 (2006) 175-179. doi:10.1108/00035590610665590.

[14] K. Allahar, Q. Su, G.P. Bierwagen, D. Battocchi, V.J. Gelling, D.E. Tallman, Examination of the Feasibility of the Use of In Situ Corrosion Sensors in Army Vehicles, in: Tri-Services Corros. Conf., 2005: pp. 1-11.

$\mathrm{http}: / /$ scholar.google.com/scholar?hl=en\&btnG=Search\&q=intitle:EXAMINATION+ $\mathrm{OF}+\mathrm{THE}+\mathrm{FEASIBILITY}+\mathrm{OF}+\mathrm{THE}+\mathrm{USE}+\mathrm{OF}+\mathrm{IN}-$

SITU+CORROSION+SENSORS+IN+ARMY+VEHICLES\#0 (accessed May 4, 2014).

[15] Y. Puget, K. Trethewey, R.J.. Wood, Electrochemical noise analysis of polyurethanecoated steel subjected to erosion-corrosion, Wear. 233-235 (1999) 552-567.

doi:10.1016/S0043-1648(99)00226-4.

[16] T. Zhang, X. Liu, Y. Shao, G. Meng, F. Wang, Electrochemical noise analysis on the pit corrosion susceptibility of $\mathrm{Mg}-10 \mathrm{Gd}-2 \mathrm{Y}-0.5 \mathrm{Zr}$, AZ91D alloy and pure magnesium using stochastic model, Corros. Sci. 50 (2008) 3500-3507.

doi:10.1016/j.corsci.2008.09.033.

[17] J.J. Kim, Wavelet analysis of potentiostatic electrochemical noise, Mater. Lett. 61 (2007) 4000-4002. doi:10.1016/j.matlet.2007.01.004.

[18] A. Aballe, M. Bethencourt, F.J. Botana, M. Marcos, Using wavelets transform in the analysis of electrochemical noise data, Electrochim. Acta. 44 (1999) 4805-4816. doi:10.1016/S0013-4686(99)00222-4.

[19] Z. Dong, X. Guo, J. Zheng, L. Xu, Calculation of noise resistance by use of the discrete wavelets transform, Electrochem. Commun. 3 (2001) 561-565. http://www.sciencedirect.com/science/article/pii/S138824810100220X (accessed October 10, 2012).

[20] H. Greisiger, T. Schauer, On the interpretation of the electrochemical noise data for coatings, Prog. Org. Coat. 39 (2000) 31-36. doi:10.1016/S0300-9440(00)00096-5.

[21] M. Moon, B. Skerry, Interpretation of corrosion resistance properties of organic paint films from fractal analysis of electrochemical noise data, J Coat. Technol. 67 (1995) 35-44. http://cat.inist.fr/?aModele=afficheN\&cpsidt=3509968 (accessed June 17, 2014). 
[22] X.F. Liu, H.G. Wang, H.C. Gu, Fractal characteristic analysis of electrochemical noise with wavelet transform, Corros. Sci. 48 (2006) 1337-1367.

doi:10.1016/j.corsci.2005.06.001.

[23] S. Reid, G.E.C. Bell, G.L. Edgemon, The use of skewness, kurtosis and neural networks for determining corrosion mechanism from electrochemical noise data, in: Corrosion/98, NACE International, 1998: p. paper no. 176.

[24] M. Halama, D. Jerolitsch, P. Linhardt, G. Fafilek, Active corrosion management in automotive industry: Hyphenation of electrochemical noise analysis with artificial neural networks - feasibility study . Part I, in: "Corrosion from Nanoscale to Plant" Eurocorr 2009, Dechema, Nice, France, 2009.

[25] J.Y. Huang, X.P. Guo, Y.B. Qiu, Z.Y. Chen, Cluster and discriminant analysis of electrochemical noise data, Electrochim. Acta. 53 (2007) 680-687. doi:10.1016/j.electacta.2007.07.058.

[26] J.Y. Huang, Y.B. Qiu, X.P. Guo, Analysis of electrochemical noise of X70 steel in Ku'erle soil by cluster analysis, Mater. Corros. 60 (2009) 527-535. doi:10.1002/maco.200805139.

[27] Q. Su, K. Allahar, G.P. Bierwagen, Embedded electrode electrochemical noise monitoring of the corrosion beneath organic coatings induced by ac-dc-ac conditions, Electrochim. Acta. 53 (2008) 2825-2830. doi:10.1016/j.electacta.2007.10.063.

[28] S.J. Mabbutt, D.J. Mills, Novel configuration for electrochemical noise measurements, Br. Corros. J. 33 (1998) 158-160.

[29] G.P. Bierwagen, Calculation of noise resistance from simultaneous electrochemical voltage and current noise data, J. Electrochem. Soc. 141 (1994) L155-L157. doi:10.1149/1.2059327.

[30] U. Bertocci, C. Gabrielli, F. Huet, M. Keddam, Noise resistance applied to corrosion measurements. I. Theoretical analysis, J. Electrochem. Soc. 144 (1997) 31-37.

[31] R.A. Cottis, S. Turgoose, J. Mendoza-Flores, The effects of solution resistance on electrochemical noise resistance measurements: a theoretical analysis, in: J.R. Kearns, J.R. Scully, P.R. Roberge, D.L. Reichert, J.L. Dawson (Eds.), Electrochem. Noise Meas. Corros. Appl. ASTM STP 1277, American socienty for testing and materials, 1996: pp. 93-100.

[32] U. Bertocci, F. Huet, Noise analysis applied to electrochemical systems, Corrosion. 51 (1995) 131-144. http://www.corrosionjournal.org/doi/abs/10.5006/1.3293585 (accessed April 17, 2013).

[33] A. Bautista, F. Huet, Noise Resistance Applied to Corrosion Measurements IV. Asymmetric coated electrodes, J. Electrochem. Soc. 146 (1999) 1730-1736. 
[34] S.S. Jamali, D.J. Mills, Studying inhomogeneity of organic coatings using wire beam multi-electrode and physico-mechanical testing, Corros. Eng. Sci. Technol. in press (2013).

[35] S. Ritter, F. Huet, R.A. Cottis, Guideline for an assessment of electrochemical noise measurement devices, Mater. Sci. 63 (2012) 297-302. doi:10.1002/maco.201005839.

[36] R. Bosch, R.A. Cottis, K. Csecs, T. Dorsch, L. Dunbar, A. Heyn, et al., Reliability of electrochemical noise measurements: Results of round-robin testing on electrochemical noise, Electrochim. Acta. 120 (2014) 379-389. doi:10.1016/j.electacta.2013.12.093. 